\title{
The comparison of frequency of the upper limb musculoskeletal disorders among patients with diabetes type II with normal cases
}

\author{
Zahra Haeri Kermani ${ }^{1}$, Seyed Mojtaba Mousavi Bazzaz², Seyed Kazem Farahmand ${ }^{3}$, Ali Akbar Raoof ${ }^{4}$
}

${ }^{1}$ MD, MPH, General Practitioner, Mashhad University of Medical Sciences, Health Centre 3, 24th Akhud Khorasani Street, Mashhad, Iran

${ }^{2}$ Associate Professor of Community Medicine and Public Health, Department of Community Medicine, Mashhad University of Medical Sciences, Mashhad, Iran

${ }^{3}$ MD, PhD, Assistant Professor of Chinese Medicine, School of Persian and Complementary Medicine, Mashhad University of Medical Sciences, Mashhad, Iran

${ }^{4}$ General Practitioner, Director of Parsian Diabetes Centre, Chamran Street, Mashhad, Iran

Type of article: Original

\begin{abstract}
Background and aim: Musculoskeletal disease, that is recognized in diabetes and diabetes mellitus (DM) has shown a higher prevalence of chronic musculoskeletal complications. This study aimed at assessing the frequency of upper limb musculoskeletal disorders among patients with diabetes type II with normal cases in Mashhad, Iran. Methods: A cross-section of 100 patients with upper limb musculoskeletal disorders were enrolled in this study. The patients were examined by a unique physician considering carpal tunnel syndrome disorder, trigger finger, adhesive capsulitis, and Dupuytren's contracture at Ghaem hospital, Mashhad, Iran in 2015. All collected data were recorded by using SPSS version 21 and were analyzed through independent-samples t-test for comparing changes, and Chi-square.

Results: In this study, the mean age was $51.7 \pm 8.7$ years old. Gender frequency was $114(57 \%)$ male, and 86 $(43 \%)$ female. There was no significant difference between groups in cases of gender frequency and mean of age ( $>0.05$ ). In evaluation of association between the two groups, there was significant difference for adhesive capsulitis, $(\mathrm{p}=0.04)$. Chi-square test showed significant association for age and adhesive capsulitis between the two groups, $(\mathrm{p}=0.040)$; but no other diabetes-related disorders, $(\mathrm{p}<0.05)$.

Conclusion: The results of this study showed that in patients with diabetes mellitus and musculoskeletal complications such as upper limb musculoskeletal abnormalities, it will lead to an increase in skeletal muscle effects in DM patients. It is recommended that musculoskeletal examination is done periodically in DM patients for identification of these disorders and necessary actions are carried out for prevention of the disorders as soon as possible.
\end{abstract}

Keywords: Diabetes type II, Musculoskeletal disorders, Upper limb

\section{Introduction}

Diabetes mellitus (DM), as an outstanding metabolic problem, is considered as an epidemic in the modern world and the majority of its morbidity and mortality is related to micro and macro vascular complications (1-3). The inability of insulin to control the blood glucose level leads to a chronic condition known as "Diabetes Mellitus" or hyperglycemia (4). Based on existing figures, more than 360 million people will have diabetes mellitus by 2030 (57). It is expected that the Middle East will undergo one of the world's greatest increases in the absolute burden of diabetes in the impending decades (8). Current tendencies show that the prevalence of type 2 DM ranges from $4.6 \%$ to $40 \%$ in the Middle East, $1.2 \%$ to $14.6 \%$ in Asia, and from $1.3 \%$ to $14.5 \%$ in Iran $(9,10)$. Today prevalence of

\section{Corresponding author:}

Associate Professor Dr. Seyed Mojtaba Mousavi Bazzaz, Department of Community Medicine, Mashhad University of Medical Sciences, Mashhad, Iran.

Tel (Landline): +98-51-38002386 / Mobile: +98-9151563604, E-mail: Mousavim@mums.ac.ir

Received: March 01, 2017, Accepted: July 14, 2017, Published: November 2017

iThenticate screening: July 15, 2017, English editing: September 27, 2017, Quality control: October 16, 2017

This article has been reviewed / commented by three experts

(C) 2017 The Authors. This is an open access article under the terms of the Creative Commons Attribution-NonCommercialNoDerivs License, which permits use and distribution in any medium, provided the original work is properly cited, the use is non-commercial and no modifications or adaptations are made. 
MD is $6 \%$ of the population in the age group of 20-75 years about 2,565,500 in Iran; anticipation is increasing and is expected to reach 5,114,900 in 2025 (11). The increasing incidence of musculoskeletal disease, which is a common cause of disability in diabetes sufferers has been documented. It predominantly affects the upper limbs, particularly the shoulders and hands. Its relationship with other complications of diabetes and glycemic control is yet undefined $(12,13)$. Several personal, occupational and psychosocial factors related to upper-extremity musculoskeletal disorders have been identified through epidemiologic studies (14). These factors are attendant in the presence of DM and so, increase the occurrence of shoulder and hand problems in the diabetic population. For most of these musculoskeletal disorders, the exact pathophysiology remains obscure. However, connective tissue disorders, neuropathy or vasculopathy could have a synergistic effect on the increased prevalence of musculoskeletal disorders in diabetes mellitus (15). Osteomuscular changes in diabetic patients have been described as follows: muscular infarction; shoulder capsulitis; calcific periarthritis shoulder; carpal tunnel syndrome; stiff hand syndrome; Dupuytren's contracture; trigger finger; diffuse idiopathic skeletal hyperostosis (DISH); and Charcot's arthropathy $(16,17)$. Youseef et al reported the prevalence rates of MSK manifestations in patients with types 1 and $2 \mathrm{DM}$ as follows: carpal tunnel syndrome (5\%), sclerodactyly (3\%), Charcot joint (4\%), limited joint mobility (6\%), stenosing tenosynovitis (5\%), shoulder capsulitis (10\%), diffuse idiopathic skeletal hyperostosis (3\%) and Dupuytren's contracture (1\%) (18). In another study, Garcilzo et al. demonstrated that osteoarthritis is the most general rheumatic form of musculoskeletal disorder in patients with DM (19). Zamani et al., in their article, show carpal tunnel syndrome (49.8\%), osteoarthritis (11.9\%), sclerodactyly (27.2\%), idiopathic skeletal hyperostosis (14.1\%), trigger finger (11.9) and adhesive capsulitis (11.9) in patients with types 1 and 2 DM in Iran (20). Evidence on musculoskeletal disorders for DM among the Iranian population is limited at present. On the other hand, most studies published in Iran have shown a statistically significant increase in musculoskeletal disorder in DM patients. But there are no collective data, and no systematic review has been performed yet. This study was aimed to assess the frequency of the upper limb musculoskeletal disorders among patients with diabetes type II with normal cases in Mashhad, Iran.

\section{Material and Methods}

\subsection{Design, participants and selection criteria}

In a cross-sectional analytical study among people referred for diabetes checkup at the Persian Diabetes Center, 100 patients were examined by a single physician considering carpal tunnel syndrome disorder, trigger finger, adhesive capsulitis, and Dupuytren's contracture at Ghaem hospital, Mashhad, Iran in 2015. Patients were block-randomized and evenly separated into diabetic patients and healthy individuals as study and the control groups, respectively. All the subjects in both groups were screened by the appropriate laboratory, and examination tests and were assessed in terms of age, gender, and occupation. Inclusion criteria were type 2 diabetic patients who referred to the Persian Diabetes Center. Exclusion criteria were having a history of other metabolic diseases, surgery, trauma and fractures of the upper limb. Sample size was calculated as 100 in accordance with the study of Douloumpakas (21), and by considering $99 \%$ of accuracy coefficient and $90 \%$ of test power. The sampling method we used was blockrandomized and it was carried out through interview, physical examination, and by experiment.

\subsection{Data collection}

All included subjects were examined by a unique physician by considering carpal tunnel syndrome disorder, trigger finger, adhesive capsulitis, and Dupuytren's contracture. Informed consent was read and signed by all cases. Carpal tunnel syndrome was diagnosed based on clinical symptoms such as pain and sensory disturbances in the thumb, index finger, middle and the outer half of the ring finger. Phalen's test was positive and it was confirmed by electromyography (EMG) and nerve conduction velocity (NCV). To identify the adhesive capsulitis, diagnostic key was the restriction on passive movements of the shoulder joint in all directions, especially rotational movements. Dupuytren's contracture and trigger finger were the diagnostic clinical symptoms by exposure to physical stressors that were quantized for each object by a team of experienced ergonomic analysts. If there was doubt in diagnosis of these symptoms, patients were referred to a rheumatologist at the clinic in Ghaem hospital.

\subsection{Data analysis}

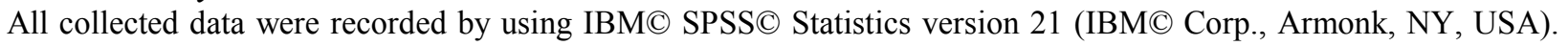
To assess descriptive statistics, indices such as frequency and relative frequency were used, and to illustrate the data, charts and tables, t-student test, and Chi-square test were used.

\subsection{Ethics of research}

Committee of Mashhad University of Medical Sciences (MUMS) approval was obtained. 


\section{Results}

\subsection{Demographic data}

The mean age was 51.7 \pm 8.7 years old and the maximum and minimum were 71 and 30 years old, respectively. Most cases $(50 \%)$ were in the 50 to 59 years age group. Gender frequency was $114(57 \%)$ male and $86(43 \%)$ female; in the DM group, 75 (75\%) cases were male and 25 (25\%) were female, however, in the control group, 39 (39\%) cases were male and $61(61 \%)$ participants were female. There was no significant difference between groups in the case of gender frequency and mean of age $(\mathrm{p}>0.05)$.

\subsection{Diabetes-related disorders}

Carpal tunnel syndrome, trigger finger, adhesive capsulitis, and Dupuytren's contracture were evaluated between groups; 12 cases in the DM group and 4 cases in the control group showed carpal tunnel syndrome, the difference was shown as significant by Chi-square, $(\mathrm{p}=0.03)$. Trigger finger was observed totally in eight persons; 5 cases in the DM group and 3 in the control group. No significant difference was observed between groups, $(p=0.36)$. Also, both groups were examined for Dupuytren's contracture disorder; only one case (2\%) in the DM group and two $(98 \%)$ cases were observed in the control group suffering from Dupuytren's contracture; Fisher's Exact Test showed that there was no significant difference, $(p=0.5)$. Adhesive capsulitis was seen in 17 cases; 13 persons in the DM group and 4 individuals in the control group. In evaluation of association between the two groups, there was significant difference for adhesive capsulitis, $(\mathrm{p}=0.02)$ (Table 1).

Table 1. Comparison of musculoskeletal disorders between DM and control groups.

\begin{tabular}{|l|l|l|l|l|l|}
\hline \multirow{2}{*}{ Disorder } & \multicolumn{2}{|l|}{ Groups } & \multirow{2}{*}{ p-value } \\
\cline { 2 - 5 } & \multicolumn{2}{|l|}{ Diabetes mellitus } & \multicolumn{2}{|l|}{ Control } & \multirow{2}{*}{} \\
\cline { 2 - 5 } & Yes & No & Yes & No & \\
\hline Carpal tunnel syndrome & 12 & 88 & 4 & 96 & 0.033 \\
\hline Trigger finger & 5 & 95 & 3 & 97 & 0.36 \\
\hline Dupuytren's contracture & 1 & 99 & 2 & 98 & 0.5 \\
\hline Adhesive capsulitis & 13 & 87 & 4 & 96 & 0.04 \\
\hline
\end{tabular}

Table 2. The association between jobs in three situations (light, moderate and heavy) and carpal tunnel syndrome, Trigger finger, Dupuytren's contracture, and Adhesive capsulitis

\begin{tabular}{|c|c|c|c|c|c|}
\hline \multirow[t]{2}{*}{ Disorder } & \multirow{2}{*}{\multicolumn{2}{|c|}{ Outcome measure }} & \multicolumn{2}{|l|}{ Groups } & \multirow[t]{2}{*}{ p-value } \\
\hline & & & Control & Diabetes mellitus & \\
\hline \multirow[t]{6}{*}{ Carpal tunnel syndrome } & \multirow[t]{2}{*}{ Light } & No & 31 & 19 & \multirow[t]{6}{*}{0.03} \\
\hline & & Yes & 0 & 7 & \\
\hline & \multirow[t]{2}{*}{ Moderate } & No & 49 & 53 & \\
\hline & & Yes & 2 & 2 & \\
\hline & \multirow[t]{2}{*}{ Heavy } & No & 16 & 16 & \\
\hline & & Yes & 2 & 3 & \\
\hline \multirow[t]{6}{*}{ Trigger finger } & \multirow[t]{2}{*}{ Light } & No & 30 & 26 & \multirow[t]{6}{*}{0.36} \\
\hline & & Yes & 1 & 0 & \\
\hline & \multirow[t]{2}{*}{ Moderate } & No & 49 & 50 & \\
\hline & & Yes & 2 & 5 & \\
\hline & \multirow[t]{2}{*}{ Heavy } & No & 18 & 19 & \\
\hline & & Yes & 18 & 19 & \\
\hline \multirow[t]{6}{*}{ Dupuytren's contracture } & \multirow[t]{2}{*}{ Light } & No & 29 & 26 & \multirow[t]{6}{*}{0.5} \\
\hline & & Yes & 2 & 0 & \\
\hline & \multirow[t]{2}{*}{ Moderate } & No & 51 & 54 & \\
\hline & & Yes & 0 & 1 & \\
\hline & \multirow[t]{2}{*}{ Heavy } & No & 18 & 19 & \\
\hline & & Yes & 18 & 19 & \\
\hline \multirow[t]{6}{*}{ Adhesive capsulitis } & \multirow[t]{2}{*}{ Light } & No & 29 & 22 & \multirow[t]{6}{*}{0.02} \\
\hline & & Yes & 2 & 4 & \\
\hline & \multirow[t]{2}{*}{ Moderate } & No & 49 & 49 & \\
\hline & & Yes & 2 & 6 & \\
\hline & \multirow[t]{2}{*}{ Heavy } & No & 18 & 16 & \\
\hline & & Yes & 0 & 3 & \\
\hline
\end{tabular}




\subsection{Frequency of disorders in terms of age, gender, and job}

According to the Chi-square test, there was no significant difference between control and DM groups for gender and diabetes-related disorders such as carpal tunnel syndrome trigger finger, and Dupuytren's contracture ( $p>0.05$ ). However, there was significant difference between the two groups in terms of gender and adhesive capsulitis, $(\mathrm{p}=0.040)$. Based on Chi-square test findings, significant association was observed for age and adhesive capsulitis between the two groups, $(\mathrm{p}=0.040)$; but no other diabetes-related disorders. We assessed the association between jobs in three situations (light, moderate and heavy) and carpal tunnel syndrome, trigger finger, Dupuytren's contracture, and adhesive capsulitis; only significant association was found between age and both carpal tunnel syndrome and Adhesive capsulitis (Table 2).

\section{Discussion}

According to the present study, we reported that the prevalence of DM is higher in males than females in intervention groups. But another study reported that DM is higher in females than in males (22). Experts reported that women in Iran generally spend most of their time at home and do less physical activities. In some studies conducted in developed countries, there is an inverse relationship between prevalence of DM and gender (23); however, our results have shown there is no significant difference between prevalence of DM and gender. Present results showed a higher prevalence of adhesive capsulitis in diabetic patients than other musculoskeletal complications in the diabetic population, by 13 cases. Prevalence of adhesive capsulitis of the shoulder is five times greater in the diabetic population than it is in the general population, being identified in $10 \%$ to $29 \%$ of the diabetic population. It appears that in type 1 and type $2 \mathrm{DM}$, it can be bilateral and is more common in elderly people (24, 25). Zabihiyeganeh and colleagues (2013) studied the frequency of upper limb musculoskeletal manifestations among 188 patients with type 2 diabetes (26); inconsistently, they reported Dupuytren's contracture as the highest prevalent disorder, and similarly Alzokm (2015) showed Dupuytren's contracture as the most frequent disorder (27). These two conflicting findings may be due to difference in chosen sample size between different studies. The most significant confounding factor is consumption of alcohol as it can lead to Dupuytren's contracture independent of its effect on the liver (28). Iranians are prohibited from drinking alcohol due to religious beliefs, and this could be the reason for its low incidence in a population such Iran. Therefore, there is need for more studies from Muslim majority regions in order to further confirm or negate these results. Various studies have reported different results about risk factors for rheumatic complications in diabetic patients; in many studies, direct association was reported between duration of disease and age (older) with rheumatologic complications. However, in this study a significant correlation was seen between adhesive capsulitis and age and gender. Tighe et al. (2008) reported that the incidence of adhesive capsulitis was two to four times higher in diabetics than in the general population in the US, and the prevalence of diabetes in patients with adhesive capsulitis was shown at 38.6\% (29); correspondingly, we found similar results. In patients with type 1 or type $2 \mathrm{DM}$, the prevalence of trigger finger ranges from $5 \%$ to $36 \%$, compared with $2 \%$ in the general population (30). We consistently found this close ratio of 5 vs. 3 . The trigger finger development has been shown that it is associated with longer disease duration $(31,32)$. We found $12 \%$ of patients suffering with carpal tunnel syndrome; Chammas (1995) and Papanas (2010) reported that it ranges from $11 \%$ to $25 \%$. These two latest studies are in alignment with our findings $(33,34)$, however, they showed that it was more common in women. The most common musculoskeletal complications were carpal tunnel syndrome, trigger finger, adhesive capsulitis, and Dupuytren's contracture among DM patients. Ordinary arthropathy endocrine disease is largely ignored or inappropriate for other complications of diabetes such as retinopathy, nephropathy or neuropathy treatment. Diabetes pathophysiological mechanisms have not been completely identified. The upper limbs, especially hand and shoulder, are most commonly involved. Identification and treatment of diabetes-related limb disorders are important to improving the life quality of patients. Furthermore, understanding the associations between them may better and easier enable the diagnosis of DM not yet recognized in patients, and as such, lead to the institution of proper therapy that can prevent the development of the complications found in diabetes. Based on reviewing the scientific literature, there is no published study examining the association between microvascular complications and rheumatologic disorders in Iran. In fact, this study revealed evidence for importance of knowledge of rheumatologic complications related to diabetes among patients with diabetes.

Current studies this year, show prevalence of DM increasing in urban regions of Iran. It is suggested public health agencies be directed towards these regions with attention on elementary prevention through lifestyle intervention. As the relatively young Iranian population ages in the future, there will likely be an increase in the prevalence of DM and other chronic diseases related to DM. Therefore, it is important to regularly monitor coronary risk factors in Iran, as well as to direct effectual public health interventions towards high-risk groups such as housewives and young girls who, in the future will become housewives. The Iranian government should focus, for the most part on 
this issue, by capitalizing and creating more adaptable and accessible jobs, and by somehow improving the standard of living in the rural areas, that can lead to decreasing the musculoskeletal complications in DM patients and a better quality of life.

\section{Conclusions}

The results of this study showed that diabetes mellitus and musculoskeletal complications such as upper limb musculoskeletal abnormalities will lead to increase in skeletal muscle effects in DM patients. It is recommended that musculoskeletal examination is done periodically in DM patients for identification of this disorder as soon as possible and necessary actions carried out for prevention of this disorder.

\section{Acknowledgments:}

The current study was internally funded by Mashhad University of Medical Sciences. We would like to thank all people who participated in this study.

\section{Conflict of Interest:}

There is no conflict of interest to be declared.

\section{Authors' contributions:}

All authors contributed to this project and article equally. All authors read and approved the final manuscript.

\section{References:}

1) Meetoo D, McGovern P, Safadi R. An epidemiological overview of diabetes across the world. Br J Nurs. 2007; 16(16): 1002-7. doi: 10.12968/bjon.2007.16.16.27079.

2) Schalkwijk CG, Stehouwer CD. Vascular complications in diabetes mellitus: the role of endothelial dysfunction. Clin Sci. 2005; 109(2): 143-59. doi: 10.1042/CS20050025.PMID: 16033329.

3) Serban AL, Udrea GF. Rheumatic manifestations in diabetic patients. J Med Life. 2012; 5(3): $252-7$. PMID: 23049626, PMCID: PMC3464992.

4) Association AD. Diagnosis and classification of diabetes mellitus. Diabetes Care. 2006; 29(1): S43.

5) Shaw JE, Sicree RA, Zimmet PZ. Global estimates of the prevalence of diabetes for 2010 and 2030. Diabetes Res Clin Pract. 2010; 87(1): 4-14. doi: 10.1016/j.diabres.2009.10.007.

6) Alvin C. Power Diabetes mellitus Harrison's principal of internal medicine. New York: McGraw Hill Publication; 2015.

7) Guariguata L, Whiting DR, Hambleton I, Beagley J, Linnenkamp U, Shaw JE. Global estimates of diabetes prevalence for 2013 and projections for 2035. Diabetes Res Clin Pract. 2014; 103(2): 137-49. doi: 10.1016/j.diabres.2013.11.002.

8) Wang W, McGreevey WP, Fu C, Zhan S, Luan R, Chen W, et al. Type 2 diabetes mellitus in China: a preventable economic burden. Am J Manag Care. 2009; 15(9): 593-601. PMID: 19747024.

9) Azizi F, Gouya M, Vazirian P, Dolatshahi P, Habibian S. The diabetes prevention and control programme of the Islamic Republic of Iran. East Mediterr Health J. 2003; 9(5-6): 1114-21. PMID: 16450545.

10) Azizi F, Guoya M, Vazirian P, Dolatshati P, Habbibian S. Screening for type 2 diabetes in the Iranian national programme: a preliminary report. East Mediterr Health J. 2003; 9(5-6): 1122-7. PMID: 16450546.

11) Sicree R, Shaw J, Zimmet P. Diabetes and impaired glucose tolerance. In: Delice Gan Diabetes Atlas. 3rd ed. International Diabetes Federation; 2007: 51.

12) Aydeniz A, Gursoy S, Guney E. Which musculoskeletal complications are most frequently seen in type 2 diabetes mellitus? J Int Med Res. 2008; 36(3): 505-11. doi: 10.1177/147323000803600315.

13) Ramchurn N, Mashamba C, Leitch E, Arutchelvam V, Narayanan K, Weaver J, et al. Upper limb musculoskeletal abnormalities and poor metabolic control in diabetes. Eur J Int Med. 2009; 20(7): 718-21. doi: 10.1016/j.ejim.2009.08.001.

14) Roquelaure Y, Ha C, Rouillon C, Fouquet N, Leclerc A, Descatha A, et al. Risk factors for upper extremity musculoskeletal disorders in the working population. Arthritis Rheum. 2009; 61(10): 1425-34. doi: 10.1002/art.24740.

15) Arkkila PE, Gautier JF. Musculoskeletal disorders in diabetes mellitus: an update. Best Pract Res Clin Rheumatol. 2003; 17(6): 945-70. doi: 10.1016/j.berh.2003.11.001.

16) Lebiedz-Odrobina D, Kay J. Rheumatic manifestations of diabetes mellitus. Rheum Dis Clin North Am. 2010; 36(4): 681-99. doi: 10.1016/j.rdc.2010.09.008. 
17) Smith L, Burnet S, McNeil J. Musculoskeletal manifestations of diabetes mellitus. Br J Sports Med. 2003; 37(1): 30. doi: 10.1136/bjsm.37.1.30. PMID: 12547740, PMCID: PMC1724591.

18) Youssef AA, Shabana AA, Senna MK, Wafa AM, Elshewehy MM. Study of musculoskeletal disorders in a cohort of Egyptian diabetic patients and its relation to glycemic control. Tanta Med J. 2016; 44(4): 151. doi: 10.4103/tmj.tmj_36_16.

19) Garcilazo C, Cavallasca JA, Musuruana JL. Shoulder manifestations of diabetes mellitus. Curr Diabetes Rev. 2010; 6(5): 334-40. PMID: 20701586.

20) Zamani B, Matini SM, Jamali R, Taghadosi M. Frequency of musculoskeletal complications among the diabetic patients referred to Kashan diabetes center during 2009-10. Feyz. 2011; 15(3): 1.

21) Azimi-Nezhad M, Ghayour-Mobarhan MP, Parizadeh MR, Safarian M, Esmaeili H, Parizadeh SM, et al. Prevalence of type 2 diabetes mellitus in Iran and its relationship with gender, urbanisation, education, marital status and occupation. Singapore Med J. 2008; 49(7): 571. PMID: 18695867.

22) Sclavo M. Physical Activity and risk for cardiovascular events in diabetic women. Ital Heart J Suppl. 2001; 2(5): 563. PMID: 11388338.

23) Douloumpakas I, Pyrpasopoulou A, Triantafyllou A, Sampanis C, Aslanidis S. Prevalence of musculoskeletal disorders in patients with type 2 diabetes mellitus: a pilot study. Hippokratia. 2007; 11(4): 216. PMID: 19582198, PMCID: PMC2552988.

24) Balci N, Balci MK, Tüzüner S. Shoulder adhesive capsulitis and shoulder range of motion in type II diabetes mellitus: association with diabetic complications. J Diabetes Complications. 1999; 13(3): 135-40. PMID: 10509873.

25) Pal B, Anderson J, Dick W, Griffiths ID. Limitation of joint mobility and shoulder capsulitis in insulin-and non-insulin-dependent diabetes mellitus. $\mathrm{Br} \mathrm{J}$ Rheumatol. 1986; 25(2): 147-51. doi: 10.1093/rheumatology/25.2.147. PMID: 3708230.

26) Zabihiyeganeh M, Ghorbanpour S, Jahed S, Golgiri F. Frequency of upper limb musculoskeletal manifestations in 188 type 2 diabetic patients, referring to diabetes clinic of Firouzgar hospital, 2011. J Babol Univ Med Sci. 2013; 16(1): 99-105.

27) Alzokm SM, Hussein A, Al Shazely SM. Assessment of Upper limb musculoskeletal complications of diabetes mellitus by Ultrasonography and nerve conduction study: Correlation with duration and severity of diabetes mellitus. J Am Sci. 2015; 11(4): 165-75.

28) Marsano LS, Vatsalya V, Hassan A, McClain CJ. Clinical Features, Disease Modifiers, and Natural History of Alcoholic Liver Disease. Alcoholic and Non-Alcoholic Fatty Liver Disease. Springer; 2016: 165-82.

29) Tighe CB, Oakley Jr WS. The prevalence of a diabetic condition and adhesive capsulitis of the shoulder. South Med J. 2008; 101(6): 591-5. doi: 10.1097/SMJ.0b013e3181705d39.

30) Yosipovitch G, Yosipovitch Z, Karp M, Mukamel M. Trigger finger in young patients with insulin dependent diabetes. J Rheumatol. 1990; 17(7): 951-2. PMID: 2213763.

31) Crispin JC, Alcocer-Varela J. Rheumatologic manifestations of diabetes mellitus. Am J Med. 2003; 114(9): 753-7. PMID: 12829202.

32) Stahl S, Kanter Y, Karnielli E. Outcome of trigger finger treatment in diabetes. J Diabetes Complications. 1997; 11(5): 287-90. doi: 10.1016/S1056-8727(96)00076-1. PMID: 9334911.

33) Chammas M, Bousquet P, Renard E, Poirier JL, Jaffiol C, Allieu Y. Dupuytren's disease, carpal tunnel syndrome, trigger finger, and diabetes mellitus. J Hand Surg Am. 1995; 20(1): 109-14. doi: 10.1016/S03635023(05)80068-1.

34) Papanas N, Maltezos E. The diabetic hand: a forgotten complication? J Diabetes Complications. 2010; 24(3): 154-62. doi: 10.1016/j.jdiacomp.2008.12.009. 